\title{
Early and Long-Term Results of Coronary Artery Bypass Grafting in Dialysis Patients
}

Objective: We evaluated the surgical outcome of coronary artery bypass grafting in dialysis patients. Methods: We retrospectively analyzed 25 consecutive dialysis patients requiring isolated coronary artery bypass grafting. Their mean age was 61.6 years and average dialysis duration 80.4 months. Results: Eight patients $(32 \%)$ had emergency or urgent surgery. The mean number of bypassed vessels was $3.3 \pm 1.2$. Internal thoracic artery grafts were used in 19 patients and gastroepiploic artery grafts in 5 . Two $(8 \%)$ died during hospitalization and complications occurred in $11(44 \%)$. No cerebral complications were observed. All survivors showed ameliorated symptoms and improved overall function. Of 14 late deaths, 5 were cardiac-related, with 2 involving obvious myocardial ischemic events. Actuarial survival, including hospital deaths, at 1 year was $70.9 \%$, at 3 years was $43.5 \%$, and at 5 years was $34.8 \%$. Cardiac-death-free survival was $70.2 \%$ at 3 years and $70.2 \%$ at 5 years. Conclusion: Coronary artery bypass grafting in dialysis patients is associated with a higher incidence of complications but has acceptable surgical mortality and effectively relieves angina symptoms. (JJTCVS 2001; 49; 660-665)

Key words: coronary artery bypass grafting, end-stage renal disease, chronic dialysis, survival, heparincoated circuit.

Shigefumi Suehiro, MD, Toshihiko Shibata, MD, Koji Hattori, MD, ${ }^{*}$ Hidekazu Hirai, MD, ${ }^{*}$ Hiromichi Fujii, MD, ${ }^{*}$ Nobuaki Aoyama, MD, ${ }^{*}$ Tsuyoshi Ikuta, MD, ${ }^{*}$ Masanori Sakaguchi, MD, ${ }^{*}$ and Hiroaki Kinoshita, MD.*

$\mathrm{M}$ yocardial infarction and other cardiac disorders remain the leading cause of death in patients with end-stage renal disease. ${ }^{1}$ With advancing age and increased incidence of diabetic nephropathy, ${ }^{1}$ cardiac surgery including coronary artery bypass grafting (CABG), is indicated in many such patients. In 1999, we showed that $\mathrm{CABG}$ or open-heart surgery in patients on maintenance dialysis could be done with acceptable risk, ${ }^{2}$ as reported elsewhere. ${ }^{3-5}$ The effectiveness of $\mathrm{CABG}$ on long-term survival in these patients remains unclear, however, because of the small number of patients in individual studies.

Here we detail our work with isolated CABG in

From the Department of Cardiovascular Surgery and the *Second Department of Surgery, Osaka City University Medical School, Osaka, Japan.

Received for publication February 13, 2001.

Accepted for publication August 2, 2001.

Address for reprints: Shigefumi Suehiro, MD, Osaka City University Medical School, 1-4-3 Asahi-machi, Abeno-ku, Osaka 5458585, Japan. patients on chronic dialysis, evaluating early mortality and morbidity with a focus on long-term survival.

\section{Subjects and Methods}

We studied 25 patients -22 men and 3 women aged 48 to 79 years (mean age: 61.6 years) - on chronic maintenance dialysis who underwent isolated CABG between April 1992 and April 2000. All were receiving hemodialysis (HD) from 4 to 204 months (mean: 80.4 months) prior to CABG. Renal failure was diabetic nephropathy $(\mathrm{n}=12)$, hypertensive nephrosclerosis $(\mathrm{n}=5)$, chronic glomerulonephritis $(\mathrm{n}=3)$, nephrotic syndrome $(\mathrm{n}=1)$, polycystic disease $(\mathrm{n}=1)$, or unknown $(\mathrm{n}=3)$ (Table I).

In all patients but one, surgery involved moderate hypothermia and aortic cross-clamping. One patient with triple vessel disease underwent off-pump CABG to the left anterior descending artery that was converted to on-pump CABG due to ventricular fibrillation. Aortic cannulation and proximal vein anastomosis sites were determined by intraoperative ultra- 
Table I. Patient profiles

\begin{tabular}{lc}
\hline Variable & $n(\%)$ \\
\hline Patients & 25 \\
Age (yrs) & $61.6 \pm 8.4$ \\
Gender (M/F) & $22 / 3$ \\
Preoperative HD & \\
$\quad$ Mean duration (months) & 80.4 \\
Range & $4-204$ \\
Causes of renal failure & \\
Diabetes mellitus & 12 \\
Nondiabetic & 10 \\
Unknown & 3 \\
Associated disease & \\
Hypertension & $20(80)$ \\
Smoking & $14(56)$ \\
Diabetes mellitus & $12(48)$ \\
Hyperlipidemia & $7(28)$ \\
CVA & $7(28)$ \\
ASO or AAA & $3(12)$ \\
\hline
\end{tabular}

$H D$, Hemodialysis; $C V A$, cerebrovascular accident; $A S O$, arteriosclerosis obliterans; $A A A$, abdominal aortic aneurysm.

Table II. Preoperative patient variables

\begin{tabular}{lc}
\hline Variable & $n(\%)$ \\
\hline Preoperative ischemia & \\
Unstable angina & $12(48)$ \\
AEMI & $1(4)$ \\
NYHA class III/IV & $9 / 12$ \\
Diseased vessels & \\
SVD/DVD/TVD & $1 / 4 / 13$ \\
Left main & 1 \\
Left main + 1VD & 1 \\
Left main + 3VD & 5 \\
Previous myocardial infarction & $11(44)$ \\
LV ejection fraction $<0.35$ & $7(28)$ \\
\hline
\end{tabular}

$A E M I$, Acute evolving myocardial infarction; SVD/ $D V D / T V D$, single, double, and triple vessel disease.

sonography of the ascending aorta. The ascending aorta was used for arterial cannulation. Surgical procedures were similar to those in nondialysis patients. All anastomoses were conducted during a single aortic clamping. Cardiac arrest was induced by cold crystalloid cardioplegia $(n=14)$ or cold blood cardioplegia $(n=11)$. In the most recent 22 patients, a heparin-coated (HC) circuit (Carmeda Bioactive Surface, Medtronic Inc., Anaheim, US) including the artificial lung (Maxima CB 1380, Medtronic) was used with reduced systemic heparinization (activated clotting time, $>300 \mathrm{~s}$ ).
Table III. Surgical variables

\begin{tabular}{lc}
\hline Variable & $n(\%)$ \\
\hline $\begin{array}{l}\text { Bypassed vessels } \\
\text { (range) }\end{array}$ & $3.3 \pm 1.2 /$ patient \\
Grafts & $(1-6)$ \\
Internal thoracic artery & $19(76)$ \\
Right gastroepiploic artery & $5(20)$ \\
Saphenous vein graft only & $5(20)$ \\
Complete revascularization & $20(80)$ \\
Elective operation & $17(68)$ \\
Urgent/emergency surgery & $2 / 6(32)$ \\
Aortic clamping time (min) & $105 \pm 32.4$ \\
Cardiopulmonary byapss time (min) & $166 \pm 45.5$ \\
Preoperative IABP support & $5(20)$ \\
\hline
\end{tabular}

$I A B P$, Intraarotic balloon pumping.

Table IV. Surgical results and postoperative complications

\begin{tabular}{lc}
\hline Variable & $n(\%)$ \\
\hline Hospital death & $2(8)$ \\
No complications & $14(56)$ \\
Complications & \\
Arrhythmia & $7(28)$ \\
Pulmonary $^{\dagger}$ & $6(24)$ \\
Mediastinitis $_{\text {Perioperative MI }}$ & $1(4)$ \\
Low output syndrome & $1(4)$ \\
Thoracotomy for bleeding & $1(4)$ \\
Delayed cardiac tamponade & $1(4)$ \\
Stroke & $1(4)$ \\
Stay in ICU (days) & $0(0)$ \\
\hline
\end{tabular}

$M I$, Myocardial infarction; $I C U$, intensive care unit. ${ }^{\dagger}$ ventilator $\geqq 3$ days, reintubation or thoracheostomy.

*median (range).

Patients who underwent elective surgery were put on HD the day before surgery. During cardiopulmonary bypass $(\mathrm{CPB})$, continuous hemofiltration was conducted using a hemofilter with replacement solution (HF-Solita, Shimizu Pharmaceutical Co., Ltd., Shizuoka, Japan). After surgery, continuous hemodialysis (CHD) was conducted through a double lumen catheter with nafamostat mesilate as an anticoagulant agent. CHD was started immediately after hemostasis was achieved. When hemodynamics stabilized, CHD was switched to maintenance dialysis. For emergency surgery, similar strategies were used intraoperatively and postoperatively.

Follow-up involved direct communication with the patient, family, attending physician, or a combination 
Table V. Early graft patency in 21 patients

\begin{tabular}{lcccc}
\hline Graft & Occluded & Stenotic & Perfectly patent & Patency (\%) \\
\hline ITA & 1 & 0 & 16 & 94.2 \\
RGEA & 0 & 1 & 3 & 75.0 \\
SVG & 1 & 1 & 50 & 96.2 \\
Total & 2 & 2 & 69 & 94.5 \\
\hline
\end{tabular}

ITA, Internal thoracic artery; $R G E A$, right gastroepiploic artery; $S V G$, saphenous vein graft.

Table VI. Late postoperative mortality

\begin{tabular}{lcc}
\hline Types of mortality & Patients $(n=14)$ & Postop. months \\
\hline Cardiac & 5 & \\
Heart failure & 2 & 11,22 \\
Acute myocardial infarction & 1 & 19 \\
Re-CABG & 1 & 16 \\
Sudden death (arrhythmia) & 1 & 67 \\
Noncardiac & 9 & $3,10,22$ \\
Infection & 3 & 31,59 \\
Cerebral bleeding & 2 & 3,66 \\
Chronic renal failure & 2 & 33 \\
Pulmonary cancer & 1 & 12 \\
Abdominal aortic aneurysm & 1 & \\
\hline
\end{tabular}

$C A B G$, Coronary artery bypass grafting.

of these. Surgery was considered an emergency when done within 24 hours of the decision to proceed with CABG regardless of patient hemodynamics. Hospital death was defined as occurring within 30 days of surgery or during the same hospital stay. Incomplete revascularization was defined as where not all graftable vessels (more than $1.5 \mathrm{~mm}$ in diameter) with severe arterial disease received a bypass graft.

Data is expressed as mean \pm standard deviation (SD), mean, or median with a range. The cumulative survival rate was calculated using the Kaplan-Meier method. Statistical significance was tested using the generalized Wilcoxon test. A P value $<0.05$ was considered significant.

\section{Results}

Subjects and procedures. Many patients were so ill that myocardial ischemia interfered with $\mathrm{HD}$, and $20(80 \%)$ had triple vessel disease or left main trunk disease (Tables II and III). Seven had a left ventricular ejection fraction less than 0.35 .

Six patients required emergency and 2 urgent CABG. Bypassed vessels numbered 1 to 6 (mean: 3.3). Left internal thoracic artery (ITA) grafts were used in 17 patients and right ITA in 2. Two arterial grafts (ITA + right gastroepiploic artery) were used in 4 patients. Five patients underwent $\mathrm{CABG}$ using saphenous vein grafts (SVG) alone. Revascularization was incomplete in 5 patients and 5 required intraaortic balloon pumping preoperatively.

Perioperative management. All patients required hemofiltration during CPB. After surgery, CHD was started within 0.5 to 5 hours in 23 patients but delayed 24 hours postoperatively in the other 2 patients because their fluids and electrolytes were balanced. CHD was switched to maintenance hemodialysis in 23 within 1 to 6 days (mean: 2.9 days). Mean CHD was $37.2 \pm 19.4$ hours. In the remaining 2 patients, CHD could not discontinued due to unstable hemodynamics.

Early results. The 2 patients who underwent elective CABG died in the hospital (8.0\%) (Table IV). The first, who was also our first HD case, developed postoperative multiple organ failure and died on postoperative day (POD) 32. The second had a left ventricular ejection fraction of 0.20 before surgery, but cardiac function did not improve even after a 5-vessel bypass. This patient also developed multiple organ failure and died on POD 55. All 5 with incomplete revascularization survived hospitalization.

Eleven patients developed postoperative complica- 


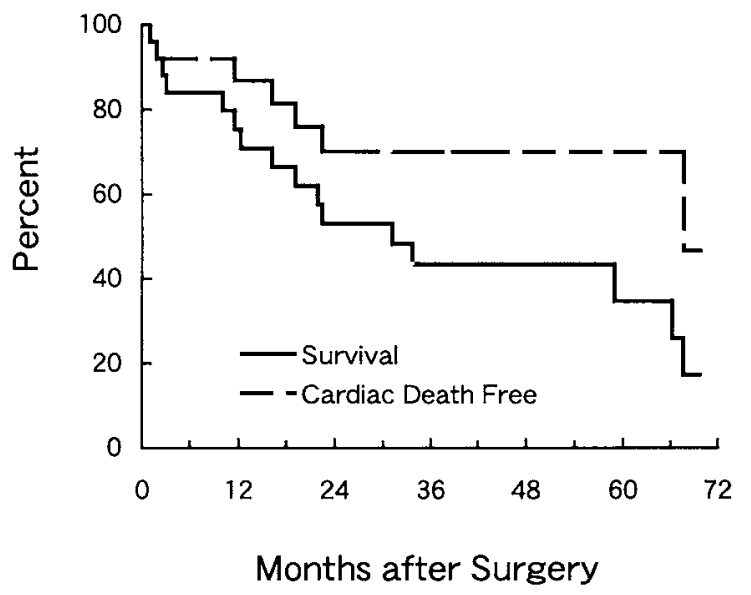

Fig. 1. Actuarial survival and cardiac-death-free curves for 25 dialysis patients undergoing isolated CABG.

tions, most frequently arrhythmias and pulmonary complications. Life-threatening arrhythmia (ventricular fibrillation) occurred in 1 patient and mediastinitis in 1. Three developing mediastinitis after discharge were managed successfully with omental transfer 35 , 56, or 66 days after CABG. Reoperation for bleeding was required in 1 patient. No cerebral complications were observed. Survivors remained in the intensive care unit from 1 to 17 days (median: 4 days).

Postoperative angiography preceding discharge showed an overall graft patency of $94.5 \%$ (69/73) with an ITA patency of $94.2 \%$ (Table V). One ITA graft used as a free graft was occluded. Overall, graft occlusion or stenosis was observed in 3 patients. One developed perioperative myocardial infarction due to occluded SVG, and 2 others were discharged with considerable relief of angina.

Long-term results. Among the 23 survivors, postoperative follow-up ranged from 3 to 68.6 months (mean: 31.2 months), with all survivors showing ameliorated symptoms and improved overall function. Among the 14 late deaths, 5 were considered cardiacrelated (Table VI). One patient undergoing successful quadruple $\mathrm{CABG}$ died of acute myocardial infarction 19 months later, another with early graft stenosis developed angina and died of low output syndrome after reCABG at another institution, and 3 died due to congestive heart failure or sudden death probably due to ventricular arrhythmia during HD. Among the 5 with incomplete revascularization, 2 died of cardiacrelated causes-congestive heart failure and sudden death.

Overall, cumulative survival, including both hospi- tal and noncardiac deaths, was $70.9 \%$ at 1 year, $43.5 \%$ at 3 years, and $34.8 \%$ at 5 years. Cardiac-death-free survival was $86.9 \%$ at 1 year, $70.2 \%$ at 3 years, and $70.2 \%$ at 5 years (Fig. 1).

Survival at 5 years was not affected by DM, emergency surgery, advanced age, HD duration, or a history of smoking.

\section{Discussion}

Early mortality of $8.0 \%$ among our patients was similar to the $7.8 \%(30 / 387)$ reported by Manabe et al. ${ }^{6}$ in metaanalysis of dialysis patients. Early mortality after $\mathrm{CABG}$ is generally higher in dialysis than nondialysis patients. ${ }^{3,5-9}$ Given that the prognosis in dialysis patients with ischemic heart disease is poor, ${ }^{10}$ we concluded that $\mathrm{CABG}$ can be conducted with slightly increased but acceptable early mortality.

Perioperative complications are reportedly more frequent in dialysis than in other CABG patients. ${ }^{7-9}$ Nearly half of our patients developed postoperative complications. As in other patients undergoing CABG, arrhythmia and pulmonary complications were most frequent. Although some previous studies ${ }^{3,9,11}$ report a high rate of cerebrovascular accidents - $7 \%$ to $11 \%$ -, none of our patients developed strokes. This favorable result was partly because we routinely evaluated the aorta ultrasonically before aortic cannulation or cross-clamping. Three patients developed mediastinitis early after discharge but causes were not clear. Dialysis patients are known to be prone to infection, ${ }^{1}$ which was a significant problem in dialysis patients undergoing $\mathrm{CABG}$.

Postoperative bleeding is a common problem after CABG in dialysis patients. ${ }^{9}{ }^{12}$ In hemodialysis or hemofiltration immediately after surgery, anticoagulant use may further promote bleeding. Hemostasis achieved intraoperatively may simplify the postoperative management. Because previous studies ${ }^{13,14}$ show that $\mathrm{HC}$ circuits with decreased doses of heparin significantly reduce blood loss, so we used HC circuits in our dialysis patients, reducing the need for reoperation due to bleeding. CHD could be started immediately after surgery and postoperative bleeding was minimized by use of an $\mathrm{HC}$ circuit and nafamostat mesilate anticoagulant in dialysis.

It is difficult to achieve complete revascularization in dialysis patients because of calcification or diffuse coronary artery disease. ${ }^{9}$ None of our 5 patients with incomplete revascularization died in the hospital or later due to myocardial ischemic events. Hosoda et 
al. ${ }^{15}$ report a low level of complete revascularization - $60 \%$ of 45 patients - and their early and late results are favorable, indicating complete revascularization may not be necessary if major coronary branches can be bypassed.

Graft materials include ITA and SVG. ${ }^{4,5,8,15}$ Except in emergencies, we used the ITA whenever possible and used the right gastroepiploic artery in patients younger than 60 years old and with severe aortic arteriosclerosis. Early graft patency was similar to that in nondialysis patients. Hosoda et al. ${ }^{15}$ report good patency with ITA grafts and SVG but little data is available on long-term patency of grafts including the ITA. Optimal graft materials thus require further evaluation. At present, we suggest that at least 1 ITA should be used in dialysis patients because of its safety and effectiveness. ${ }^{5,16,17}$

Calcification of the ascending aorta is another problem in dialysis patients undergoing CABG. ${ }^{5}$ With severe aortic calcification, surgical procedures such as CABG under ventricular fibrillation or an aortic nontouch method may be necessary. ${ }^{5}$ Thanks to ultrasonic aortic evaluation, we were able to conduct $\mathrm{CABG}$ as usual manner. Off-pump CABG can benefit dialysis patients, but its application should be carefully evaluated because it may be difficult due to the distal coronary artery disease frequently found in dialysis patients.

Survival of $34.8 \%$ at 5 years in our patients is well within the range of previous reports: Franga et al., ${ }^{9}$ $32 \%$; Marshall et al., ${ }^{11} 48 \%$; Kaul et al., ${ }^{3} 56 \%$; and Frenken et al., ${ }^{4} 67 \%$. Approximately $50 \%$ of patients are alive overall at 5 years. Mortality of $9.4 \%$ at 1 year is reported in the general dialysis patient population and actuarial survival of approximately $60 \%$ after 5 years of dialysis ${ }^{1}$ - similar to dialysis patients undergoing $\mathrm{CABG}$. Neither ours nor previous studies proved that $\mathrm{CABG}$ prolongs life expectancy in dialysis patients, but no data is available on the natural history of patients who are candidates for CABG. The majority of patients undergoing CABG had lifethreatening myocardial ischemia and, conceivably, a worse life expectancy than the general dialysis patient population. Postoperative relief of angina is excellent and ongoing, ${ }^{3-5,11,15,16}$ indicating that $\mathrm{CABG}$ improves the prognosis in dialysis patients.

Previous studies ${ }^{4,5,8}$ report that nearly half of late deaths in CABG patients are due to cardiac events. In our study, the rate of noncardiac deaths was comparatively high, ${ }^{4,5,8}$ but only 2 died of obvious myocardial ischemic events. Our cardiac-death-free survival of
$70 \%$ at 5 years was acceptable. To improve long-term survival, strategies are needed, however, to prevent and control specific problems in dialysis patients.

In conclusion, we believe the short-term and longterm results of CABG surgery in dialysis patients are acceptable. Owen et al. ${ }^{8}$ suggest that the relative costs and benefits of CABG need further examination in this patient population, however, since long-term survival is limited. Therapeutic strategies, including indications for surgery, must be established. Examination of these strategies in a larger number of patients will be undertaken in the future.

\section{REFERENCES}

1. Japanese Society for Dialysis Therapy. An overview of dialysis treatment in Japan (as of Dec. 31, 1996) (Eng abstr). J Jpn Soc Dialysis Ther 1998; 31: 1-24.

2. Suehiro S, Shibata T, Sasaki Y, Murakami T, Hosono M, Fujii H, et al. Cardiac surgery in patients with dialysis-dependent renal disease. Ann Thorac Cardiovasc Surg 1997; 5: 376-81.

3. Kaul TK, Fields BL, Reddy MA, Kahn DR. Cardiac operations in patients with end-stage renal disease. Ann Thorac Surg 1994; 57: 691-9.

4. Frenken M, Krian A. Cardiovascular operations in patients with dialysis-dependent renal failure. Ann Thorac Surg 1999; 68: 887-93.

5. Nakayama Y, Sakata R, Ura M, Miyamoto TA. Coronary artery bypass grafting in dialysis patients. Ann Thorac Surg 1999; 68: 1257-61.

6. Manabe S, Sunamori M, Sakamoto T, Tanaka H, Ohshima S, Hasegawa S, et al. Coronary arterial revascularization in dialysis patients (Eng abstr). Kyobu Geka 2000; 53: 825-30.

7. Ko W, Kreigner KH, Isom OW. Cardiopulmonary bypass procedures in dialysis patients. Ann Thorac Surg 1993; 55: 677-84.

8. Owen CH, Cummings RG, Sell TL, Schwab SJ, Jones $\mathrm{RH}$, Glower DD. Coronary artery bypass grafting in patients with dialysis-dependent renal failure. Ann Thorac Surg 1994; 58: 1729-33.

9. Franga DL, Kratz JM, Crumbley AJ, Zellner JL, Stroud MR, Crawford FA. Early and long-term results of coronary artery bypass grafting in dialysis patients. Ann Thorac Surg 2000; 70: 813-9.

10. Hellerstedt WL, Johnson WJ, Ascher N, Kjellstrand CM, Knutson R, Shapiro FL, et al. Survival rates of 2,728 patients with end-stage renal disease. Mayo Clin Proc 1984; 59: 776-83.

11. Marshall WG, Rossi NP, Meng RL, Wedige-Stecher T. Coronary artery bypass grafting in dialysis patients. Ann Thorac Surg 1986; 42: S12-5.

12. Zamora JL, Burdine JT, Karlberg H, Shenaq SM, Noon GP. Cardiac surgery in patients with end-stage renal 
disease. Ann Thorac Surg 1986; 42: 113-7.

13. Øvrum E, Åm Holen E, Tangen G, Brosstad F, Abdelnoor M, Ringdal ML, et al. Completely heparinized cardiopulmonary bypass and reduced systemic heparin: clinical and hemostatic effects. Ann Thorac Surg 1995; 60: 365-71.

14. Suehiro S, Shibata T, Sasaki Y, Hattori K, Kumano H, Hosono M, et al. Use of heparin-coated bypass circuit with low-dose heparin reduces postoperative bleeding. Ann Thorac Cardiovasc Surg 1999; 5: 225-9.

15. Hosoda H, Yamamoto T, Takazawa K, Yamasaki M, Yamamoto S, Hayashi I, et al. Coronary artery bypass grafting in patients on chronic hemodialysis: surgical outcome in diabetic nephropathy versus nondiabetic nephropathy patients. Ann Thorac Surg 2001; 71: 5438.

16. Koyanagi T, Nishida H, Endo M, Koyanagi H. Coronary artery bypass grafting in chronic renal dialysis patients: intensive perioperative dialysis and extensive usage of arterial grafts. Eur J Cardiovasc Surg 1994; 8: 505-7.

17. Blakeman BP, Sullivan HJ, Foy BK, Sobotka PA, Piafarre R. Internal mammary artery revascularization in the patient on long-term renal dialysis. Ann Thorac Surg 1990; 50: 776-8. 